Int Arch Allergy Immunol 1997;113:390-392

\title{
Subject Index, Vol. 113, No.1-3, 1997
}

\section{$-3,1997$}

International Archives of

Allergy-Immunology

Adhesion molecule 203 Adolescents 87 Aeroallergens 379 Air pollution 65, 69 Allelic exclusion 11

Allergen(s) 30, 69, 80, 102, 105, 109, 114, 122,236,243

- $\quad$ structure 240

Allergen-monomethoxypolyethyleneglycol

conjugates 58, 323 Allergic contact dermatitis 384

inflammation 51,150

rhinitis 281

Allergy 7, 14, 55, 65, 69, 75, 153, 213, 264,

302,345, 352 Allervax ${ }^{\circledR}$, cat allergy 224, 326 Alternaria 114 Amyloid 295 Anaphylaxis 14, 337

Animal dander 83 Antiallergic drug 321 Antigen challenge 318 Antigen-specific $\gamma / \delta$ T cells 373

Antigenic determinant 99

- $\quad$ variants 99

Anti-idiotypic antibodies 216

Anti-IgE 45,216,231,305

Apoptosis 196,206

Arachidonic acid 190

Arahl 118

Aspergillusfumigatus 213

Aspirin 355

Asthma 65, 83, 87, 102, 181, 193, 287, 318,

$323,355,366,376$ Atopic dermatitis 24, 209

eczema 379

patients 305 Atopy 39, 80, 209

patchiest 379 Autoimmunity 153,209

Basophils 134, 181,262 Betvl 125,170,243,252,260 Birch pollen 105 B lymphocytes 35

Bradykinin 131 Bronchial asthma 51, 370

- $\quad$ epithelial cells 203, 307

Bronchoalveolar lavage 65,318

Bronchoconstriction 231

Bronchopulmonaryhyperresponsiveness

231

C3 368

C3b 368

CD4 T cell memory 281

CD4+ 163,227 


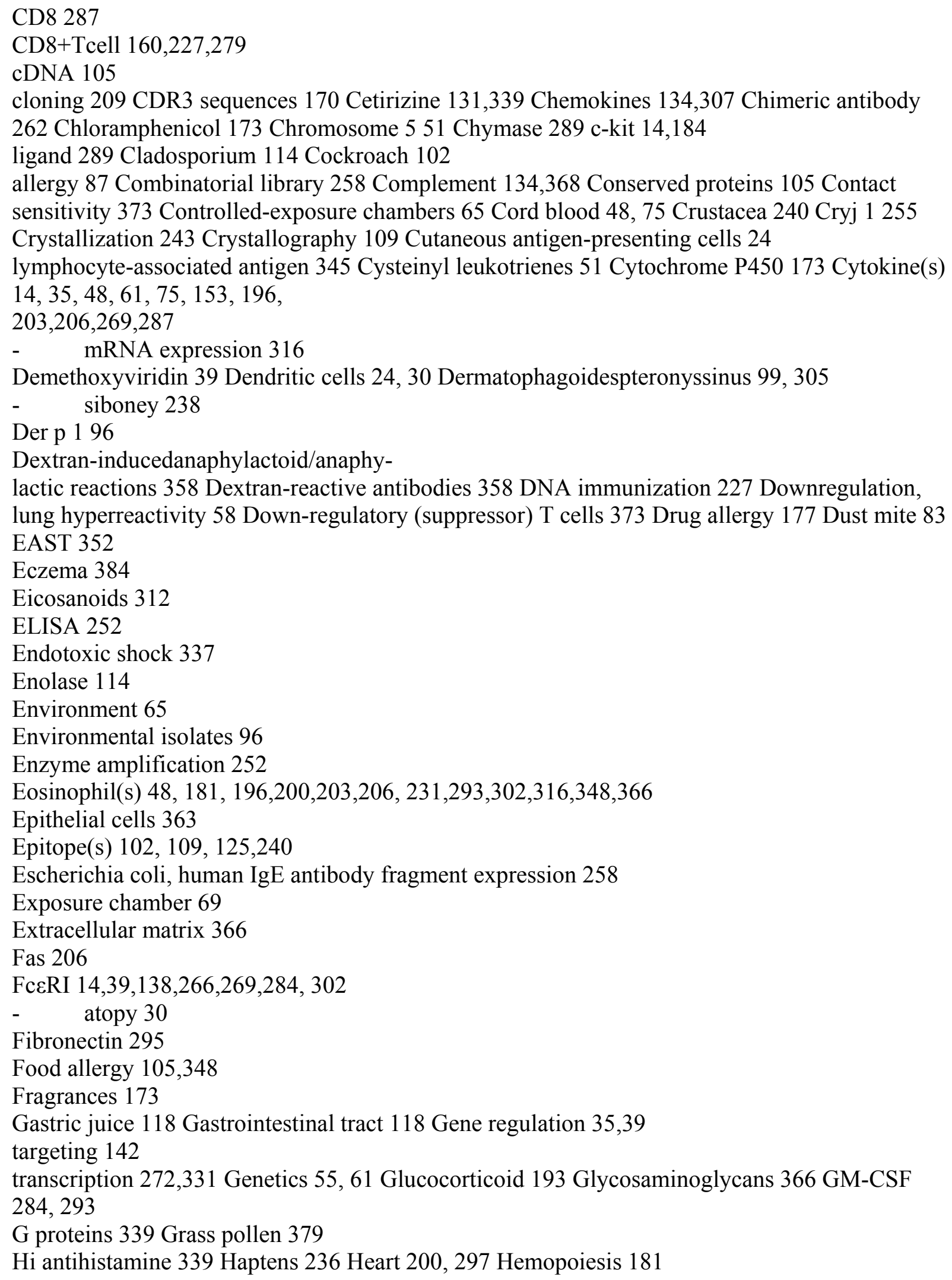


Histamine 131, 187, 200, 264, 284, 297

receptor antagonist 321

release $45,262,305,335$

-, beta carotene 335 Histamine-releasing factors 187 HLA 255

HMC-1 287,363 Homing 345 House dust mite 96

KA PvG E R (C) 1997 S. Karger AG, Basel

E-Mail kargcr@kargcr.ch Fax+4161306 1234 http://www.karger.ch

Human monocytes 266

- $\quad$ nasal mucosa 312

Hu-SCID mouse 150

iC 3 b 368

IFN- $\gamma 255,275,287$

$\operatorname{IgE} 5,35,55,128,142,150,160,216,231,246,258,262,266,279,329,376$

antibodies $14,99,342$

autoantibodies 209

binding 260

receptors $24,48,376$

suppression 227 IgE-facilitated allergen presentation 24 IgG 138

antibodies 342,358

subclasses 252 IL-2 167,275

receptor 167

IL-4 61, 134, 163, 187, 196,255,287,

321,329,384 IL-5 177, 181, 196,272,287,293,

331 IL-6 307

receptor 300 IL-8 307 IL-12 163,281 IL-13 134, 187 Immature, mature B cells 11 Immune

complexes 358

regulation $160,219,231,279$

response 80 Immunization 281 Immunoglobulin synthesis 167 Immunotherapy 224, 246, 255

Inactivation, cutaneous and pulmonary

mast cells 58 Indoor allergens 83 Infections 153 Inflammation 181, 206 Inflammatory bowel disease 348 Influenza virus 307 Inhalation therapy 370 In situ hybridization 128 Intestinal anaphylaxis 348 Intradermal skin test 360 Isoform 125 Isoproterenol 370

Laminin 295 Langerhans cells 30 Late-phase allergic reaction 293 Late-phase response 376

Leukotriene C4 51

- $\quad$ - synthase 355

Leukotrienes 312

Lidocaine 177

Lifestyle 7

Limiting dilution analysis 281 Lolium perenne 305

Lung function 65

- $\quad$ inflammation 316

Lymphocyte transformation test 173

Macrophages 300 Major allergen 240

birch pollen allergen 260

grass pollen allergens 258 Mastcell(s) 14, 39, 138, 184, 200, 269, 284, 287, 289, 291, 293, 295, 297, 335, 348, 
363 Mast-cell-deficient mice 14 Mastocytosis 184,289 Matrix metalloproteases 366

- $\quad$ metalloproteinase 318

Mediator release 14, 291, 352

Membrane immunoglobulins 142

MHC class I 279

Microdialysis 131

$\mathrm{m}^{1 / 8 \mathrm{D}} 146 \mathrm{~m}^{1 / 8} \mathrm{M} 146$ Mimotopes 216 Mite 102

allergens 238 MnSOD 213 Molecular biology 102

mechanism 193

structure 243 Monoclonal antibody 45,260 Monocytes 173,300,335 Monomethoxypolyethylene glycol 58, 323 Mononuclear cell 193

Moulds 114 Mutagenesis 99

N-acetyl-L-cysteine 329 Nasal allergy 128

- $\quad$ lavage 65

Neuroimmunology 337

Neutrophils 190,316,337,368

NF-AT 272

Nickel-sulfate 384

Nitric oxide 297 Northern blot 300

Nuclear magnetic resonance spectroscopy 243

Oligoclonality 177 Ozone 65,312

Pan-allergen 213

Parasites 7

Peanut 118

Penal 240

Penaeus aztecus 240

Penicillins 342

Peptide(s) 96, 224, 255, 326

Pesticides 352

Phage display library 216

/?-Phenylenediamine 173

Phi pi 170

Phlp2 109

Phosphoinositol-3 kinase 39

Pollen 69, 236, 264

Pollen-pollutant interaction 69

Pollinosis 255

Pollutants 264

Pollution 7

Postnatal immune responses 252

Pre-B receptor 11

Prick test 264

Profilin 109

Prohibitin 146

Prohibitone 146

Promoter 61,272,331 
Prostaglandin 312

Proteoglycans 366

Raf kinase 275

Rat Sephadex model 316

rBet v 1249

rBetv2 249

Reactivity, codeine 360

-, histamine 360

Recombinant allergen 240

Arahl 118

birch pollen allergen (Bet v 1) 246

Fab 260

IgE-Fabs 258

proteins 122 Retinoicacid 167 Rhinitis 376

Salivary glands 337 Sequence polymorphisms 96 Serine esterases 291 Signal transduction 39, 206 Single-chain T cell receptors 170 Skin 131,345

prick tests 352

reaction 231

testing $246 \mathrm{~S} \mu-\mathrm{S} \varepsilon$ switching 11 Socioeconomic status 87 Solutol 335

Specific IgE 249 Stem cell factor 14, 184 Sulfamethoxazole 177 Sulfidoleukotriene 305

Sulfonamides 173 Sulfur dioxide 69 Superantigen 150 Surrogate light L chain 11

Tcell 96,167,177,272,275,331

- differentiation 163

- epitopes 96

- line 255

- tolerance 326

- vaccine 246

Subject Index

Int Arch Allergy Immunol Vol. 113, 1997

391

$\gamma / \delta$ T cells 373 Tertiary structure 99 Thl 150,160

cells 163

interferon- $\gamma$ responses 373

response, plasmid DNA immunization 227

$\mathrm{Thl} / \mathrm{Th} 275,281$

cells 153 Th2 134,150, 160,329

cells 163 Thiols 329

THP1 266 Thromboxane 312 Tissue 269

inhibitor, metalloproteinases $318 \mathrm{~T}$ lymphocyte(s) $125,345,384$

- clone 287 Tolerance/suppression 75 Transcription 61

factors 35

Transepidermal water loss 379 Transgenic foods 122 Triglycerides 190

Tryptase 200, 284, 289, 363 Tumor necrosis factor alpha 39 Type I allergy 246

Vaccination 216

Wortmannin 39 
Xenobiotics 352 X-ray 243

Int Arch Allergy Immunol Vol. 113, No. 1-3, 1997

Subject Index 